\title{
Clinical Observations on the Effects of Debrisoquine Sulphate in Patients with High Blood-Pressure
}

\author{
D. ATHANASSIADIS,* M.D. ; W. I. CRANSTON,* M.A., M.D., F.R.C.P. \\ B. E. JUEL-JENSEN,* M.A., B.M., CAND.MED.; D. O. OLIVER,* M.B., M.R.C.P., M.R.A.C.P.
}

Brit. med. F., 1966, 2, 732-735

Debrisoquine sulphate (3,4-dihydro-2 (1H)-isoquinoline carboxamidine sulphate; Declinax) is a new synthetic hypotensive agent which causes post-ganglionic sympathetic blockade without measurably altering the noradrenaline or 5-hydroxytryptamine content of rat heart or brain (Moe et al., 1964). In this respect it resembles bretylium rather than guanethidine, but it differs from bretylium in so far as it does not promote the uptake of tritiated noradrenaline by heart muscle. Debrisoquine has been shown to reduce arterial pressure in animals (Moe et al., 1964) and in patients with hypertension (Abrams et al., 1964 ; Bryant et al., 1965). It causes a fall in supine arterial pressure and a greater fall on standing, with abolition of the pressor overshoot after the Valsalva manœuvre. We report here the results obtained with this drug in a group of hypertensive patients.

\section{Materials and Methods}

Non-pregnant Patients. - Debrisoquine was given to 22 men and 23 women whose ages ranged from 18 to 74 years. Twenty-two patients had benign essential hypertension, 9 benign renal hypertension, and 14 malignant hypertension (9 essential and 5 renal) (Table I). Thirty-one patients had received other hypotensive drugs before debrisoquine: 18 had guanethidine or ganglion-blocking agents, 4 methyldopa, 6 diuretics, and 3 rauwolfia alkaloids. Twelve patients, including 7 with malignant hypertension, had not been treated before. The diastolic blood-pressures measured in the standing position after exercise are shown in Table I. Patients were treated with debrisoquine over periods of two weeks to 15 months; 10 for over 12 months, and 29 for more than six months.

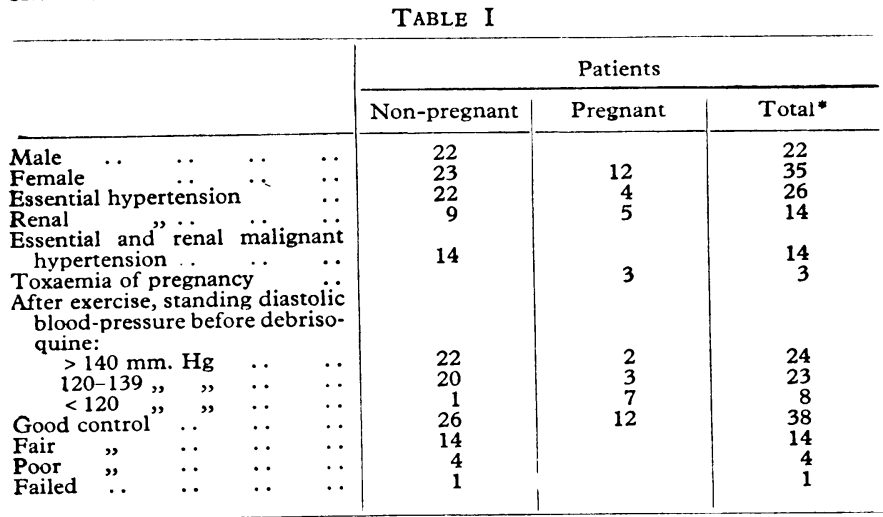

- Two patients were assessed pregnant and non-pregnant

Pregnant Patients.-Twelve women aged from 18 to 43 were treated with debrisoquine during 13 pregnancies; five had hypertension associated with renal disease, one with superimposed toxaemia, four had hypertension during pregnancy without albuminuria, and three had toxaemia of pregnancy without either underlying renal disease or essential hypertension.

- From the Department of the Regius Professor of Medicine, Radcliffe Infirmary, Oxford.
Before treatment with debrisoquine nine women had received other hypotensive agents-seven had diuretics and two guanethidine and diuretics. In these patients debrisoquine was either added to the diuretics or substituted for guanethidine, the long duration of activity of guanethidine being considered undesirable in late pregnancy. During pregnancy debrisoquine was used for periods ranging from 9 days to 34 weeks. In 10 patients it was used only during pregnancy. Two patients with severe hypertension continued this treatment post partum. One patient with a slightly raised blood urea had a nonfunctioning kidney removed without effect on the bloodpressure: she has continued debrisoquine for one year. The other patient continued debrisoquine after a stillbirth and throughout a second successful pregnancy for a total of 17 months. These two patients are included in the non-pregnant and pregnant groups. All patients with hypertension and pregnancy began treatment in hospital.

Acute changes of blood-pressure in response to oral and intravenous administration of debrisoquine were measured in three patients by means of a continuous blood-pressure recorder (Richardson et al., 1964). Otherwise, blood-pressures were measured by sphygmomanometer with the patients recumbent, upright, and after exercise. Exercise consisted in running up and down one flight of 25 steps, but no attempt was made to control the rate at which the patients carried out the exercise.

Our definition of blood-pressure control was based on the average of all blood-pressure measurements after the dose of debrisoquine was first stabilized, as follows:

Good Control: Average standing diastolic blood-pressure below $101 \mathrm{~mm}$. $\mathrm{Hg}$, or at least $41 \mathrm{~mm}$. $\mathrm{Hg}$ below the pretreatment level.

Fair Control : Average standing diastolic blood-pressure 101 to $110 \mathrm{~mm}$. $\mathrm{Hg}$, or at least 21 to $40 \mathrm{~mm}$. Hg below the pretreatment level.

Poor Control : Average standing diastolic blood-pressure over $110 \mathrm{~mm}$. $\mathrm{Hg}$, or 11 to $20 \mathrm{~mm}$. $\mathrm{Hg}$ below the pre-treatment level.

Failure : No significant change in diastolic blood-pressure.

\section{Results}

\section{Effect of a Single Dose of Debrisoquine}

A single intravenous dose of 20 or $40 \mathrm{mg}$. of debrisoquine was given on only three occasions, because each caused an initial rise of blood-pressure accompanied by headache, nausea, and distress. The blood-pressure rise was in the region of $70 \mathrm{~mm}$. $\mathrm{Hg}$ systolic and $30 \mathrm{~mm}$. $\mathrm{Hg}$ diastolic, which lasted for about one-half to one hour (Fig. 1). A single oral dose of $40 \mathrm{mg}$. of debrisoquine reduced the blood-pressure for 8 to 12 hours, the maximum effect occurring between the second and eighth hours (Fig. 1). Initial elevation of the blood-pressure following oral debrisoquine was not observed. The hypotensive action was greater in the erect than in the supine position, and exercise caused a pronounced fall ir blood-pressure. 


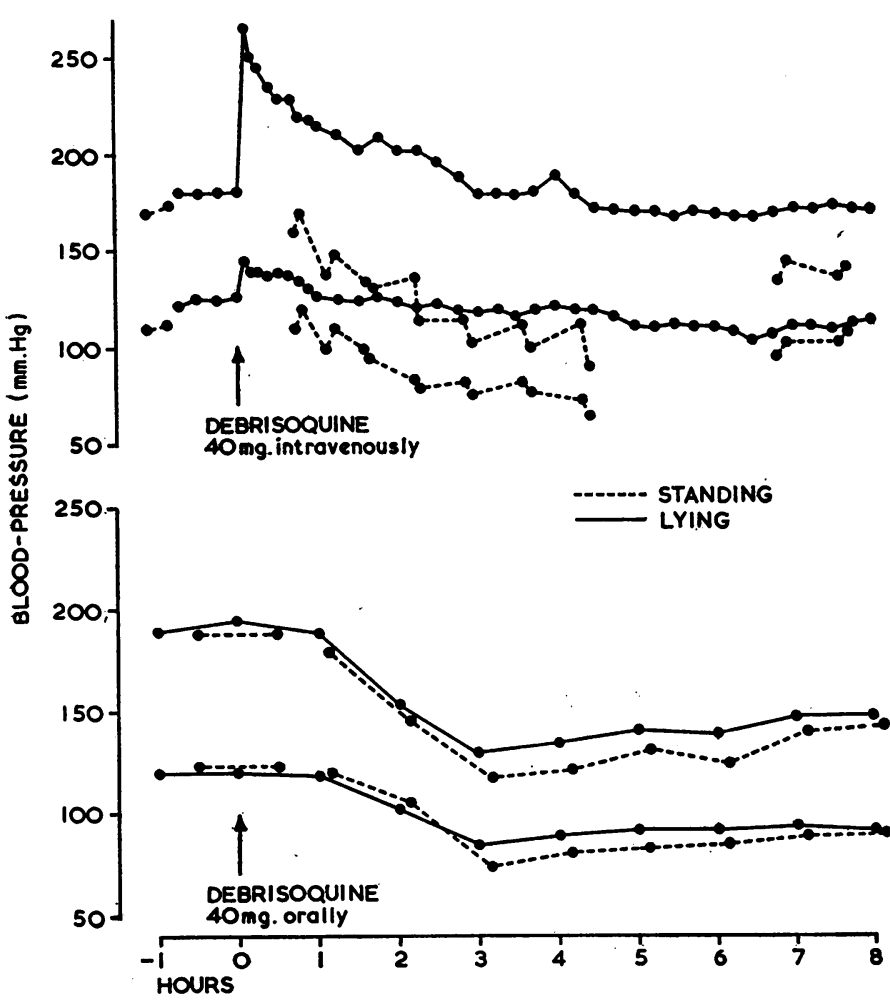

FIG. 1.-Effect of intravenous and oral debrisoquine on standing and lying arterial blood-pressures.

\section{Long-term Treatment of Hypertension with Debrisoquine}

Ten patients have taken debrisoquine for more than 12 months-five for 9 to 12 months and 14 for 6 to 9 months. The remaining 26 patients have received debrisoquine for less than six months, 10 being women with hypertension in pregnancy. The results are shown in Table $I$.

The daily dose of debrisoquine ranged from 10 to $360 \mathrm{mg}$. Initially debrisoquine was given in two or three equal doses at 6 a.m., midday, and 6 p.m., but on this regimen there was a tendency for the evening pressures to be high, or postural hypotension occurred in the mornings in patients with adequately controlled blood-pressure during the rest of the day. Latterly the daily dose of debrisoquine was given as a small dose in the morning, a relatively large dose at midday, and a moderate evening dose, with good blood-pressure control throughout the day and few side-effects.

\section{Control of Blood-pressure}

In 41 patients treated for more than three months bloodpressure control was good in 22 , fair in 14 , poor in 4 , and a failure in one.

Many of the patients previously treated with other hypotensive agents had also received diuretics, and the latter were continued when the change to debrisoquine was made. Four patients were given diuretics after a stable dose of debrisoquine was attained: in three there was a further fall in bloodpressure.

Development of tolerance was measured by comparing patients treated for three to eight months with those treated for more than nine months in respect of blood-pressure control and the dose of drug. Patients treated for more than nine months had a slightly higher dose of debrisoquine than those treated for shorter periods, and their blood-pressures were slightly less well controlled. This was believed to be a manifestation of tolerance, although it has not yet posed a serious problem. Fig. 2 shows the blood-pressures in the standing position, and doses of debrisoquine in nine patients who continued to take the drug regularly for 12 months or longer. Progressive tolerance developed in patients 2 and 6 , but not in the remainder. When the diastolic blood-pressures after exercise were studied in a similar manner there was less evidence of tolerance.

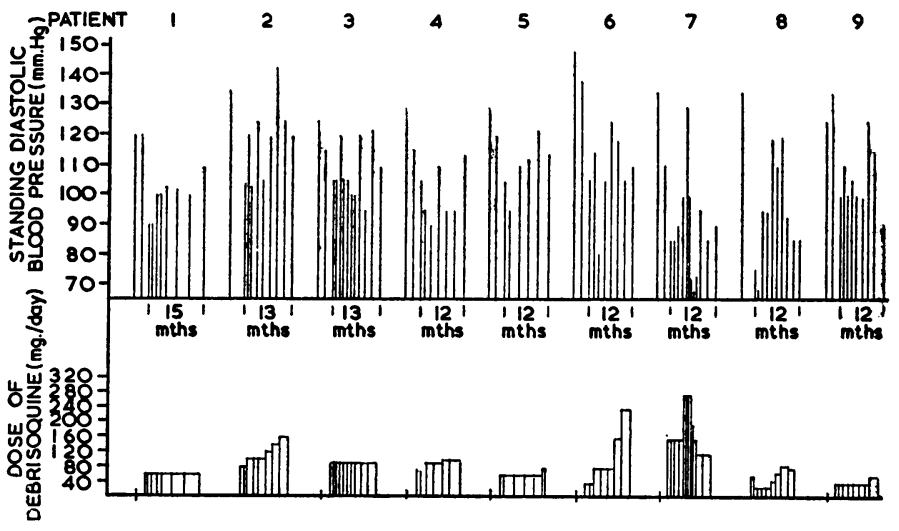

FIG. 2.-Effect of long-term therapy with debrisoquine on diastolic arterial blood-pressures.

\section{Side-effects}

Side-effects fall into two categories: first, hypotension on standing or exercise directly due io the intended action of the drug ; secondly, effects apparently unrelated to the bloodpressure, and in this sense true side-effects. The incidence of side-effects in all 55 patients is shown in Table II, together with assessment of blood-pressure control.

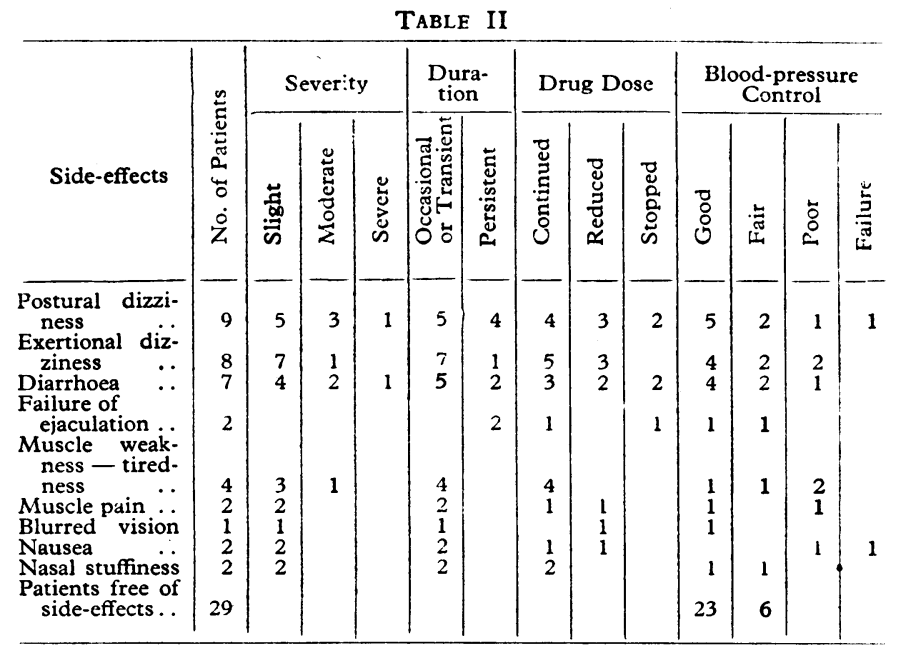

Nine patients complained of dizziness on standing or on exercise, mainly in the mornings ; in five this did not persist, and four continued with the same dose of debrisoquine. For this reason in three patients the drug was reduced, and in two discontinued. Eight patients noted dizziness only on exercise, and although the dose was reduced in three patients this remained a troublesome side-effect in one patient. Diarrhoea with watery stools and an urgent desire to defaecate, particularly in the mornings, was noted in seven patients ; debrisoquine was stopped in two and reduced in another two because of this effect. Two patients complained of failure of ejaculation, and treatment was stopped in one of them on this account. One man, however, previously unable to ejaculate during treatment with guanethidine, had no difficulty in this respect during treatment with debrisoquine, though his blood-pressure remained well controlled. A sensation of tiredness or muscleweakness was noticed by four patients; in two this occurred 
only in the mornings, and it passed off in all of them after a few days, without reducing debrisoquine. Two patients complained of pain in the shoulder and pelvic-girdle muscles during exercise. One patient had blurred vision, relieved by reducing the dose of debrisoquine. Nausea occurred in two cases, and in one the dose was reduced on this account. Nasal congestion for a short period after starting the drug was experienced by two patients. One patient had pain in the chest on drinking sherry. None of the patients complained of facial pain.

Renal function was assessed by the blood urea. With two exceptions there was no evidence of impaired renal function after reduction of arterial pressure with debrisoquine, although in five patients the blood urea was over $60 \mathrm{mg} . / 100 \mathrm{ml}$. before treatment. In two patients progressive renal failure from chronic pyelonephritis caused death, but there was no evidence that treatment aggravated the renal failure. Haemoglobin levels and white-cell counts were normal throughout treatment.

\section{Weight Changes}

Although there was considerable scatter the average weight did not change significantly, whether or not patients received diuretics. Recently two patients increased their weight by over $10 \mathrm{lb}$. (4.5 kg.) during the first two weeks' treatment with debrisoquine. This was accompanied by a fall in the haematocrit and haemoglobin and elevation of the jugular venous pressure. It appeared therefore that debrisoquine may cause fluid retention in some patients.

\section{Deaths}

Six patients died while receiving debrisoquine. Two died of progressive renal failure due to chronic pyelonephritis, and one died of a bronchial carcinoma, which was diagnosed before treatment was started. Two patients died suddenly at home; post-mortem examination showed a recent cerebral infarct in one, and in the other it was not performed.

\section{Debrisoquine in Pregnancy}

The blood-pressure response was good in each patient (Table I). In seven patients labour was induced, and in two caesarean section was performed, but in neither was foetal distress or complications of pregnancy responsible for ending the pregnancy. Debrisoquine was stopped 24 to 48 hours before induction of labour or caesarean section, and in the other patients it was discontinued at the start of labour. All deliveries were uncomplicated.

Two patients had stillbirths. One intrauterine death occurred at the 34th week, after treatment with guanethidine for 12 weeks and debrisoquine for 10 days. Debrisoquine was continued before and during a subsequent pregnancy, caesarean section being performed at 34 weeks; the infant and placenta were normal for the period of gestation. The other stillbirth occurred at the 35 th week of pregnancy in a patient with severe hypertension of renal origin with superimposed toxaemia of pregnancy.

Seven of the 11 infants had birth weights below $5 \mathrm{lb}$. $(2,270$ g.) related to induced delivery before term, otherwise they were normal. One premature and one full-term infant had slight difficulty starting respiration.

\section{Comparison with Guanethidine}

Eighteen of the patients had previously been treated with guanethidine, 10 receiving thiazide diuretics with both drugs, three having thiazides with guanethidine but not with debrisoquine, and one who had previously been treated with guanethidine alone subsequently received debrisoquine with a thiazide diuretic. Most of these patients were given debrisoquine because treatment with guanethidine was unsatisfactory.

In five patients guanethidine caused severe and persistent diarrhoea, inadequately controlled by codeine phosphate. In four patients changed to debrisoquine diarrhoea was relieved and codeine phosphate was discontinued; in three this was associated with better blood-pressure control, and in one without change in pressure. Diarrhoea persisted in one patient after changing to debrisoquine. One patient, whose blood-pressure could not be adequately controlled by guanethidine because of fluid retention, lost weight and showed adequate blood-pressure control when changed to debrisoquine.

In the remaining patients morning or exercise hypotension limited the use of guanethidine, usually without controlling the blood-pressure during the rest of the day. In these patients, with one exception, good control of the blood-pressure was achieved with debrisoquine without postural hypotension. This improvement was the result of giving the main dose of debrisoquine at midday.

\section{Discussion}

The evidence available shows that debrisoquine has an effect similar to that of guanethidine on the arterial pressure of patients with hypertension. The main difference is in the duration of action of the drug. Debrisoquine acts over a period of 8 to 12 hours after oral administration. In some respect this is a disadvantage, since the drug has to be taken two or three times daily ; in other respects it is advantageous, since it permits more flexible control of blood-pressure at different times of the day. Furthermore, debrisoquine is indicated when rapid blood-pressure control is mandatory: when severe hypertension is associated with malignant retinopathy, heart failure, or neurological abnormalities. It is likely that 0.25 to $0.5 \mathrm{mg}$. of debrisoquine per $\mathrm{kg}$. by mouth would control the blood-pressure within a few hours in most instances.

This drug has many of the drawbacks of the ganglionblocking agents: hypotension on standing or on exercise may limit the effectiveness of control of the blood-pressure at all times of the day. In this trial many patients treated with debrisoquine had been unsatisfactorily controlled by other hypotensive agents ; the change to this drug made satisfactory blood-pressure control possible, and there was relative freedom from troublesome side-effects. However, the patients studied were not representative of the usual range of patients receiving medical treatment for hypertension.

We have not observed serious toxic effects from debrisoquine, and this has been the experience of others (Abrams et al., 1964 ; Luria and Freis, 1965 ; Buzzi, 1965 ; Bryant et al., 1965). Oral treatment with debrisoquine has been reported to cause little change in renal plasma-flow and glomerular filtration rate (Abrams et al., 1964), although Onesti et al. (1964) state that cardiac output, renal blood-flow, and glomerular filtration rates were decreased. Though we have not made any measurements of this kind, none of our patients showed any evidence of renal or cardiac deterioration which could be attributed to the drug.

Our impression to date is that debrisoquine is at least as effective a hypotensive agent as guanethidine. It is possible that tolerance may yet be a significant problem with this drug, but in view of the results in patients treated for over one year this seems to be an unusual event. In some patients it has proved superior to guanethidine, causing less diarrhoea, though this has not been demonstrated unequivocally.

\section{Summary}

Fifty-five hypertensive patients, including 12 pregnant women, were treated with debrisoquine, a new short-acting 
post-ganglionic sympathetic-blocking drug. Debrisoquine is as effective as guanethidine as a hypotensive drug: it has fewer side-effects than the latter, while a shorter duration of action may be an advantage in certain circumstances.

\section{REFERENCES}

Abrams, W. B., Pocelinko, R., Klausner, M., Hanauer, L., and Whitman, E. N. (1964). F. New Drugs, 4, 268.
Bryant, J. M., Fletcher, L., jun., Schvartz, N., Fertig, H., and Quan, R. B. F.' (1965). F. Amer. med. Ass., 193, 1021.

Buzzi, A. (1965). Med. panamer., 23, 61.

Luria, M. H., and Freis, E. D. (1965). Curr ther Res, 7, 289. Moe, R. A., Bates, H. M., Palkoski, Z. M., and Banziger, R. (1964).

Ibid., 6, 299.

sti, G., Brest, A. N., Novack, P., Ramirez-Muxo, O., and Moyer, J. H. (1964). Circulatzon, 30, p. 135.

Richardson, D. W., Honour, A. J., Fenton, G. W., Stott, F. H., and Pickering, G. W. (1964). Clin. Sci., 26, 445.

\title{
Clinical Evaluation of Oral Long-acting Isoprenaline in Treatment of Heart-block
}

\author{
M. M. EL-NAHAS, ${ }^{*}$ M.R.C.P.ED. ; A. M. JOHNSON, $\dagger$ M.D., M.R.C.P.
}

The need for a safe and effective treatment of heart-block has long been recognized. Of the many drugs used isoprenaline hydrochloride has, since its introduction by Nathanson and Miller (1952), been the most promising one, and the one most carefully studied.

Since the first reports of the use of a slow-release oral preparation (Saventrine) in the treatment of heart-block (Dack and Robbin, 1961 ; Corday et al., 1962 ; Fleming and Mirams, 1963) we have been investigating this preparation on a clinical basis, and we now present the results of assessment of its use in a larger series of cases treated since June 1962. A similar study was reported by Bluestone and Harris (1965). The active principle, in the form of small granules, is first coated with varying numbers of layers of ethyl cellulose separated by talc. The coated granules are then incorporated into tablets, each containing $30 \mathrm{mg}$. of isoprenaline hydrochloride. Ethyl cellulose is insoluble in the fluid contents of the gastro-intestinal tract, but water-absorption causes the layers to expand and disintegrate. This process is independent of $p \mathrm{H}$, gastrointestinal mobility, and variation in intestinal enzymes. The active ingredient is released slowly, for intestinal absorption, over a period of eight hours after the administration of a single dose.

Isoprenaline hydrochloride (Isupren, isoproterenol U.S.P., isopropylnoradrenaline) is 1-(3,4-dihydroxyphenyl)-2-isopropylaminoethanol. It possesses an isopropyl group on the terminal nitrogen of the side-chain in place of the methyl group of adrenaline. It is a sympathomimetic amine, the stimulant action of which on the heart is its only sympathomimetic action which might be classified as excitatory. It is a vasodilator, a bronchial dilator, and it inhibits intestinal and uterine motility. It has been used by the subcutaneous, intravenous, sublingual, and rectal routes in the treatment of heart-block.

Intravenous injection of $0.02 \mathrm{mg}$. of isoprenaline in complete heart-block produces an increase of the ventricular rate for a few minutes, while the effect of subcutaneous injection lasts one to two hours, and with sublingual administration the action starts in 15 to 30 minutes and lasts for 45 to 120 minutes. The action of isoprenaline is similar to that of adrenaline (epinephrine) but is less likely to produce ectopic beats and is more sustained (Nathanson and Miller, 1952). Unlike adrenaline, it rarely moves the idioventricular pacemaker more distally (Chandler and Clapper, 1959). While adrenaline may precipitate ventricular tachycardia or fibrillation, isoprenaline

\footnotetext{
* Registrar in Cardiology, Wessex Cardiac and Thoracic Centre, Chest Hospital, Southampton.

† Consultant Cardiologist, Wessex Cardiac and Thoracic Centre, Chest Hospital, Southampton.
}

has a predominant effect upon the high idioventricular or supraventricular pacemaker and is less likely to do so (Adelman et al., 1957). It increases cardiac output and lowers systemic vascular resistance, so that the mean systemic arterial pressure shows little change. The increase of cardiac output may be due to an increase of the heart rate or to stimulation of the strength of myocardial contraction, or to both factors (Stack et al., 1958), and this appears to be the case both in the normal heart and in the presence of complete atrioventricular block. There is a greater effect on the sinoatrial pacemaker than on nodal or ventricular foci (McGaff et al., 1959), so that the accelerating effect is greatest in the normal.

\section{Material and Management}

Twenty-one patients (14 males, 7 females) were selected for this treatment over three years and there have been 26 trials. The ages of the patients varied from 5 to 76 years. Two patients had ischaemic heart disease, three had primary myocardial disease, and one had calcific disease of the mitral and aortic valves. In two the heart-block was post-operative, following total correction of Fallot's tetralogy, and in 13 the cause was unknown. The presenting symptom in all cases was that of inefficient cerebral perfusion in the form either of Stokes-Adams attacks or of prolonged confusional states. Five patients had heart failure as well. In 18 cases the heart-block was complete and in three it was partial or varying in degree. Attacks of ventricular tachycardia were considered to contraindicate the use of this preparation, which otherwise was given a trial in every case. The initial dosage given was usually $30 \mathrm{mg}$. six-hourly (120 mg./day), and this was increased if necessary, usually every two to three days, to a maximum of $120 \mathrm{mg}$. four-hourly $(720$ mg./day). The pulse rate was recorded every hour, E.C.G.s were obtained at least once daily, and a careful watch was kept for side-effects. The goal, of course, was to produce a stable and sufficient idioventricular rate with the fewest possible sideeffects. With patients who required artificial pacemaking from the start, we carried out the same regimen in the hope that we might be able to take them off the pacemaker later.

\section{Case Reports}

Two cases, each illustrating a particular aspect or problem, are described below.

Case 13.-An 8-year-old boy, operated on for total correction of Fallot's tetralogy, developed complete heart-block on the operating-table. He had suffered from left hemiplegia and epileptic 